
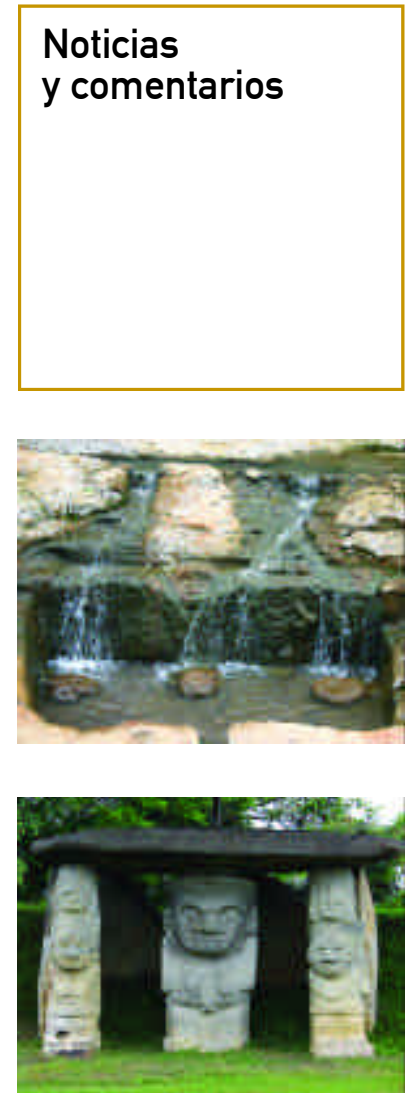

Parque Arqueológico de San Agustin, Huila (Colombia), Imagen: Ada Barandica

\title{
Colombia da a conocer el Parque de San Agustín con un Congreso de Turismo Arqueológico
}

El Parque Arqueológico de San Agustín e Isnos (Colombia) fue declarado Patrimonio Mundial en 1995, y hasta 1997 tuvo una afluencia de turistas de forma ascendente. A partir de esa fecha y debido a problemas de orden público, entiéndase guerrilla, fue decayendo el turismo de forma brusca ante el miedo y la inseguridad de los visitantes, pero en la actualidad ese problema ha sido paliado en esta zona del país con un control de seguridad bastante alto. Debido a esta situación vivida en San Agustín en los últimos años, la población y los regidores tenían gran interés por la celebración de un congreso que pusiera de nuevo en valor, ante la comunidad nacional e internacional, el Parque Arqueológico de San Agustín e Isnos.

El Congreso Internacional de Turismo Arqueológico (16 al 18 de junio de 2005) tuvo su presentación en Neiva y se celebró en San Agustín.

El encuentro -propiciado por la Universidad Externado de Colombia en colaboración con el Ministerio de Cultura, la Gobernación del Huila y el Instituto Colombiano de Antropología e Historia (ICANH)- contó con la participación de un numeroso grupo de conferenciantes colombianos e internacionales.

A lo largo del primer día del Congreso se fueron sucediendo las conferencias de los ponentes internacionales, que fueron tratando casos específicos de turismo arqueológico, bien fueran proyectos concretos o planes de protección y de manejo. En el segundo día se procedió a la visita de los Parques Arqueológicos de San Agustín e Isnos y tuvieron lugar las mesas de trabajo en torno a la gestión de dichos parques. El tercer día comenzó con una mesa redonda, compuesta por expertos colombianos, sobre la gestión del turismo arqueológico; posteriormente se pasó a la elaboración de conclusiones y recomendaciones por parte de los invitados internacionales, en las que se reiteraron ideas tan fundamentales como la necesidad de investigación, conservación y difusión en un proceso de puesta en valor. Sin un proceso de investigación no se puede conocer realmente de dónde se parte y con qué valores se cuenta; además permite tener una visión auténtica de la realidad que se contempla. En segundo lugar, se destacó la importancia de la conservación, tanto en su carácter curativo como preventivo, fundamentales ambos para la preservación de la pieza. Y en tercer lugar, pero no menos importante, se subrayó la difusión como factor esencial para el conocimiento de la labor realizada con anterioridad. Sin difusión, otras actuaciones pierden sentido. Difundir es conservar: se protege, se cuida y se valora lo que se conoce.

También se hizo especial hincapié en otro aspecto fundamental referente a los Parques Arqueológicos: no están aislados, están insertos en un espacio y hay que entenderlos como tales, en un contexto. Hay que hacer un proceso de análisis de las potencialidades para llevar a cabo un desarrollo conjunto del territorio, diversificando la oferta y evitando mimetizar esquemas.

El Congreso cumplió con su función de conocer experiencias sobre turismo arqueológico de otras latitudes, a la vez que se daba a conocer este magnífico Parque Arqueológico de San Agustín, asiento principal de la cultura agustiniana, que surgió hacia el segundo milenio a.C. y se desarrolló hasta el 700 d.C. El Parque, además de contar con unas excepcionales tumbas y esculturas megalíticas, presenta el potencial de un excepcional enclave: el Macizo Colombiano, un espacio de gran diversidad entre paisajes montañosos y profundos cañones del río Magdalena.

Julio Rodríguez Bisquert

Departamento Formación y Comunicación del IAPH

\section{Cádiz acoge una jornada técnica sobre el valor económico de la Cultura}

Agentes de desarrollo local, técnicos de gestión cultural, técnicos de unidades de promoción de empleo, investigadores y universitarios tuvieron la oportunidad el pasado 22 de julio de debatir en torno a las implicaciones económicas y culturales durante una Jornada Técnica organizada en El Puerto de Santa María (Cádiz) por la Asociación de Empresarias y Profesionales de la provincia y la Consejería de Cultura de la Junta de Andalucía.
También hay que subrayar las exposiciones de José Bersaluce, Socio Director de la empresa Archivos de Andalucía S.L., que explicó cómo con una base académica del ámbito de las humanidades puede encontrar su desarrollo profesional a través de la puesta en marcha de una arriesgada pero exitosa iniciativa empresarial, y de Daniel Lorenzo, Profesor Titular de Organización de Empresas de la Universidad de Cádiz, acerca del Proyecto GEM 
(www.gemconsortium.org), actividad en la que participan universidades de 34 paises, entre ellos España (www.ie.edu/gem/index.html), con el objetivo de realizar un estudio anual, mediante una metodología investigadora, de la capacidad de creación de empresas en un territorio. Andalu-cía interviene en este proyecto desde el año 2003 a través de la Universidad de Cádiz (www.gem-andalucia.org); se pretende, para el informe del año 2005, dedicar un epigrafe exclusivo a la creación de empresas en esta comunidad vinculadas a la cultura.

Del encuentro derivaron las siguientes conclusiones:

$>$ Economización de la cultura para concienciar de la relación totalmente posible y necesaria de estos dos términos.

$>$ Culturización de la economía. Concienciar a los agentes económicos que intervienen en el desarrollo económico de las regiones de que la cultura también genera empleo, ideas emprendedoras de éxito y en definitiva riqueza económica.
> Formación económica y empresarial de forma transversal para todas las áreas académicas de la universidad, especialmente a aquellas áreas con menos tradición economicista como son las titulaciones de humanidades, cuyos egresados cada vez más establecen su objetivo profesional en la creación de empresas que tienen como base la cultura (puesta en valor del patrimonio cultural, gestión de proyectos, turismo cultural...).

> Formación de verdaderos profesionales capaces de gestionar el rico patrimonio cultural a través de proyectos viables en los que predomine la sensibilidad y no la especulación.

$>$ Necesaria transferencia de los resultados obtenidos a través de la investigación universitaria a los colectivos vinculados a la economía y la cultura.

> Creación de empresas culturales como claro indicador del valor económico de la cultura.

Carmen Jorge Delgado

Departamento Formación y Comunicación del IAPH

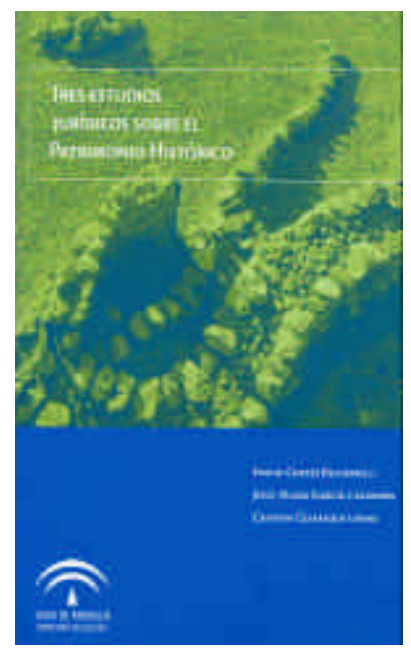

\section{Cultura aborda la protección jurídica del patrimonio en sus últimas publicaciones}

La Dirección General de Bienes Culturales de la Consejería de Cultura ha publicado, entre sus últimos títulos, el libro Tres estudios jurídicos sobre el patrimonio histórico, compuesto por dos trabajos sobre la protección penal del patrimonio arqueológico y un tercer estudio que ofrece un análisis comparativo de los distintos modelos de protección penal del patrimonio cultural.

Con esta publicación, la Consejería de Cultura de la Junta de Andalucía aborda una temática nueva en su linea editorial y pone de relieve la necesidad de avanzar en el estudio relacionado con el ámbito jurídico patrimonial. En Tres estudios jurídicos sobre el patrimonio histórico, Emilio Cortés Bechiarelli realiza un análisis crítico en torno al contenido del concepto de patrimonio arqueológico, y las posibilidades de cobertura penal a partir del estudio del art. 46 de la Constitución Española, referente básico para el desarrollo jurídico posterior. Como es el caso del Código Penal de 1995, analizado por Jesús María García Calderón en el segundo estudio que compone esta publicación, código que introduce una nueva categoría delictiva expresamente referida a la preservación del Patrimonio Histórico Español. Por último, el trabajo de Cristina Guisáosla Lerma reflexiona sobre los modelos de protección penal desarrollados en otros paises como Francia, Italia y Alemania, así como el estado de la cuestión en el Derecho norteamericano e inglés.

Ante la evidencia de la necesidad de sancionar las conductas atentatorias contra el Patrimonio Cultural, el legislador debe tomar la decisión sobre la técnica legal a la que acudir para la más completa y eficaz protección. Los Estados se hallan ante la siguiente alternativa: acudir a una legislación especial, de base administrativa y penal, o proceder a la tipificación en el Código Penal, bien otorgando una tutela directa y específica de los bienes culturales como tales -modelo por el que en principio se ha decantado nuestro legislador- o bien adoptando un sistema de tutela indirecta, donde el Patrimonio Cultural no recibe protección como bien jurídico autónomo, sino que aparece cobijado en diversos espacios sistemáticos del Código Penal, estructurándose generalmente a través de agravaciones de figuras delictivas comunes domo daños, incendios, hurtos o robos.

Las otras novedades editoriales de la Consejería se centran en proyectos de salvaguarda del patrimonio arqueológico: Carta Arqueológica Municipal de San Fernando, Guía del Yacimiento Arqueológico de Cercadilla (Córdoba) y El horizonte cultural megalítico en el área de Huelva, trabajos de investigación que evidencian la ingente labor que en materia de arqueología se está desarrollando en Andalucía. Por último, la publicación Pintura rupestre levantina en Andalucía. Catálogo es fruto del reconocimiento de la importante presencia del arte rupestre en Andalucía.

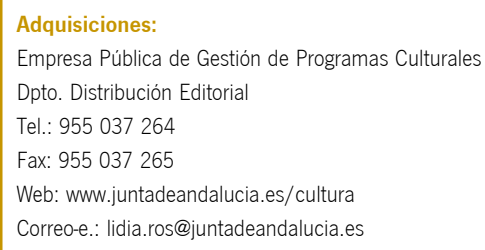

